\title{
Effect of Powerpoint Media Use on Cognitive Learning Results of Mathematics About Multiplication as Repeated Summation in Grade 2 Students Elementary School
}

\section{Anjas Murwani}

SD Negeri 2 Semawungdaleman

anjasmurwani@gmail.com

Article History

accepted 01/11/2020

approved 08/11/2020

published 15/11/2020

\begin{abstract}
The purpose of this study is to illustrate whether the use of media powerpoint can affect the results of learning math in elementary school grade 2. This type of research is class action research in three cycles with each cycle consisting of two meetings. The stages of each cycle are planning, implementation, observation and reflexion. Data analysis techniques are quantitative descriptive. Each meeting is carried out pre test and post test to get the development of education. In cycle I the percentage of post tests of the complete number of students is 52\%. In cycle II the percentage of post tests of the complete number of students is $95 \%$. And in cycle III the percentage of post tests of the total number of students completed by $95 \%$. The results showed that powerpoint media can improve the results of learning mathematics about grade II multiplication at SDN 2 Semawungdaleman.
\end{abstract}

Keywords: learning results, math, Media Powerpoint

\section{Abstrak}

Tujuan dari penelitian ini adalah untuk menggambarkan apakah penggunaan media powerpoint dapat mempengaruhi hasil belajar matematika di sekolah dasar kelas 2. Jenis penelitian ini adalah penelitian tindakan kelas dalam tiga siklus dengan setiap siklusnya terdiri dari dua pertemuan. Tahapan setiap siklusnya adalah perencanaan, pelaksanaan, observasi dan reflesi. Teknik analisis data berupa deskriptif kuantitatif. Setiap pertemuaan dilaksanakan pre test dan post test untuk mendapatkan perkembangan perserta didik. Pada siklus I prosentase post test dari jumlah siswa yang tuntas sebesar $52 \%$. Pada siklus II prosentase post test dari jumlah siswa yang tuntas sebesar $95 \%$. Dan pada siklus III prosentase post test dari jumlah siswa yang tuntas sebesar $95 \%$. Hasil penelitian menunjukkan bahwa media power point dapat meningkatkan hasil belajar matematika tentang perkalian sebagai penjumlahan berulang kelas II di SDN 2 Semawungdaleman.

Kata Kunci: hasil belajar, matematika, Media Powerpoint

Social, Humanities, and Education Studies (SHEs): Conference Series https://jurnal.uns.ac.id/shes

p-ISSN 2620-9284

e-ISSN 2620-9292 


\section{PENDAHULUAN}

Pendidikan merupakan salah satu hal yang penting bagi kehidupan suatu bangsa. Kualitas suatu bangsa ditentukan oleh kualitas dari pendidikan yang berlangsung di dalamnya. Oleh karena itu pendidikan memiliki peran yang sangat penting dalam meningkatkan kualitas suatu negara. Peran dari pendidikan ialah dapat meningkatkan sumber daya manusia, mewujudkan kesejahteraan umum dan mencerdaskan kehidupan bangsa.

Pendidikan terus berjalan sepanjang manusia itu hidup dan sadar tentang keberadaannya dalam suatu lingkungan. Memaknai hal tersebut, maka konsep pendidikan sepanjang hayat sangat penting dalam kehidupan manusia untuk memenuhi kebutuhan belajar dan kebutuhan pendidikan. Pendidikan sepanjang hayat juga harus mengikuti dan selalu terbuka terhadap perkembangan zaman. Saat ini perkembangan teknologi sangatlah pesat dimana menuntut pendidikan untuk terus maju dan beradaptasi dengan cepat. Seperti yang tertera didalam UU No.20 tahun 2003 Pendidikan adalah usaha dasar dan terencana untuk mewujudkan suasana belajar dan proses pembelajaran agar peserta didik secara aktif mengembangkan potensi dirinya untuk memiliki kekuatan spiritual keagamaan, pengendalian diri, kepribadian, kecerdasan, akhlak mulia, serta keterampilan, yang diperlukan dirinya, masyarakat, dan negara.

Pendidikan yang baik dikarenakan hasil belajar yang diperoleh siswa baik pula. Hasil belajar diperoleh dari kegiatan belajar. Belajar adalah kegiatan berproses dan merupakan unsur yang sangat fundamental dalam penyelenggaran jenis dan jenjang pendidikan, hal ini berarti keberhasilan pencapaian tujuan pendidikan sangat tergantung pada keberhasilan proses belajar siswa di sekolah dan lingkungan sekitarnya (Jihad, 2010). Hasil belajar tersebut bisa dalam ranah kognitif, afektif, dan psikomotor. Hasil belajar kognitif yaitu hasil belajar yang ada kaitannya dengan ingatan, kemampuan berfikir atau intelektual. Menurut Anas Sudijono dalam bukunya Pengantar Evaluasi Pendidikan, mengemukakan bahwa "ranah kognitif adalah ranah yang mencakup kegiatan mental (otak)". Jadi ranah kognitif merupakan ranah yang bekerja dalam bidang mental (otak) yang berkaitan dengan proses mental bagaimana impresi dari suatu panca indera dicatat dan disimpan dalam otak. Seperti halnya ketika berfikir, mengingat, dan memahami sesuatu. Begitu juga menurut Menurut Muhibbin Syah dalam bukunya Psikologi Pendidikan dengan Pendekatan Baru, mengemukakan bahwa: Kognitif berasal dari kata cognition yang padanan katanya knowing, yang berarti mengetahui . Dalam arti yang luas, kognitif adalah perolehan, penataan, dan penggunaan pengetahuan. Dalam perkembangan selanjutnya, istilah kognitif menjadi populer sebagai salah satu domain atau wilayah/ranah psikologis manusia yang meliputi setiap perilaku mental yang berhubungan dengan pemahaman, pertimbangan, pengolahan informasi, pemecahan masalah, kesengajaan, dan keyakinan Hasil belajar kognitif matematika sampai saat ini masih dianggap sebagai salah satu komponen penting siswa berhasil dalam pendidikan di Indonesia meski juga termasuk mupel yang menakutkan.

Betul adanya bahwa pelajaran matematika merupakan salah satu pelajaran yang penting dan menakutkan. Anak-anak akan merasa tidak mampu dahulu ketika sudah berhadapan dengan mupel satu ini. Memberikan permasalahan yang menyangkut dengan konteks sehari-hari tidaklah cukup untuk membuat peseta didik cepat dalam memahami suatu soal matematika. Di sekolah dasar, sebagian besar materi pelajaran disampaikan secara konvensional sehingga materi terlihat kurang menarik. Agar materi terlihat lebih menarik dan memotivasi siswa untuk belajar diperlukan sebuah inovasi pembelajaran.

Oleh karena itu seorang pendidik harus dapat memanfaatkan kecanggihan dari teknologi sehingga menciptakan media pembelajaran yang inovatif dan interaktif untuk 
meningkatan hasil belajar peserta didik. Media adalah bagian yang tidak terpisahkan dari proses belajar mengajar demi tercapainya tujuan pendidikan pada umumnya dan tujuan pembelajaran di sekolah pada khususnya". Gagne dan Briggs (dalam Azhar Arsyad, 2014: 4) Atas dasar teori tersebut maka media merupakan salah satu komponen penting dari proses pembelajaran. Media pembelajaran yang menggunakan teknologi canggih dan menarik sikap, minat dan motivasi peserta didik diharapkan dapat memenuhi kebutuhan belajar para peserta didik yang beragam. Sehingga tujuan pembelajaran dapat tercapai dengan maksimal. Salah satu media pembelajaran yang dapat digunakan adalah microsoft powerpoint. Razaq (dalam Sukiman, 2012:213) mengemukakan bahwa dengan Microsoft Office Power Point ini kita dapat merancang dan membuat presentasi yang lebih menarik dan profesional Selanjutnya seperti yang dikemukakan oleh Riyana (2008: 102) sebagai berikut. Program Microsoft office powerpoint adalah salah satu software yang dirancang khusus untuk mampu menampilkan program multimedia dengan menarik, mudah dalam pembuatan mudah dalam penggunaan dan relatif murah karena tidak membutuhkan bahan baku selain alat untuk menyimpan data (data storage).Media ini dapat menampilkan materi yang tidak hanya menyuguhkan tampilan secara visual saja ataupun audio saja. Fasilitas yang disuguhkan oleh microsoft powerpoint bisa juga berupa animasi yang bukan hanya berlaku pada teks saja tapi bisa pada gambar, garis, video, film dan sebagainya.

Pada observasi awal saat pembelajaran dengan tidak menggunakan media power point minat belajar peserta didik kurang dalam penguasaan materi pembelajaran sehingga menjadikan hasil belajar tidak tercapai maksimal yaitu dari 21 peserta didik hanya sekitar 10 peserta didik yang dapat memahami konsep perkalian dengan penjumlahan berulang.

Perlunya inovasi dalam pembelajaran ini tentunya diharapkan dapat mempengaruhi hasil belajar kognitif matematika tentang perkalian sebagai penjumlahan berulang pada siswa kelas 2 SD N 2 Semawungdaleman tahun pelajaran 2020/2021. Berdasarkan latar belakang masalah di atas maka rumusan permasalahan yang diperoleh yaitu pertama, bagaimanakah pengaruh penggunaan media power point terhadap hasil belajar kognitif matematika tentang perkalian sebagai penjumlahan berulang pada siswa kelas 2 SD N 2 semawungdaleman tahun pelajaran 2020/2021 Kedua, apakah pengaruh penggunaan media power point terhadap hasil belajar kognitif matematika tentang perkalian sebagai penjumlahan berulang pada siswa kelas 2 SD N 2 Semawungdaleman tahun pelajaran 2020/2021? Dan ketiga, apa kendala dan solusi pengaruh penggunaan media power point terhadap hasil belajar kognitif matematika tentang perkalian sebagai penjumlahan berulang pada siswa kelas 2 SD N 2 Semawungdaleman tahun pelajaran 2020/2021? Dari rumusan permasalah tersebut diperoleh tujuan penelitian yaitu untuk mendeskripsikan apakah penggunaan media power point dapat mempengaruhi hasil belajar kognitif matematika tentang perkalian sebagai penjumlahan berulang pada siswa kelas 2 SD N 2 Semawungdaleman tahun pelajaran 2020/2021. 


\section{METODE}

Penelitian ini adalah penelitian tindakan kelas (Classroom Action Research) yang menggunakan media powerpoint sebagai media pembelajaran. Subjek penelitian ini siswa kelas II SD N 2 Semawungdaleman tahun pelajaran 2020/2021 yang berjumlah 21 siswa, yang terdiri dari 11 siswa laki- laki dan 10 siswa perempuan Desain penelitian ini menggunakan model Kemmis dan Mc. Taggart (dalam Wardhani dkk:2007). Penelitian ini dilaksanakan dalam tiga siklus. Setiap siklus terdiri perencanaan, pelaksanaan, observasi, dan refleksi. . Teknik pengumpulan data adalah observasi, analisis data tes hasil belajar, dan dokumentasi. Instrumen penelitian menggunakan lembar tes hasil belajar, lembar observasi, dan kamera. Teknik analisis data yang digunakan yaitu deskriptif kuantitatif. Indikator keberhasilan penelitian ini adalah minimal $75 \%$ dari seluruh siswa yang mengikuti pembelajaran dimana telah mencapai taraf kriteria ketuntasan minimal yang ditentukan yaitu mencapai nilai $\geq 70$. Pembelajaran dilaksanakan secara luring. Siklus I dilaksanakan pada tanggal 21 dan 22 Oktober 2020. Siklus II dilaksanakan pada tanggal 2 dan 3 November 2020. Siklus III dilaksanakan pada tanggal 12 dan 13 November 2020. Teknik pengumpulan data yang dilakukan dengan observasi, tes (pre-test dan post-test) dan dokumentasi. Observasi meliputi observasi kelas dan keterlaksanaan penggunaan media pembelajaran. Untuk hasil belajar menggunakan tes tertulis yang diberikan langsung ke peseta didik

\section{HASIL DAN PEMBAHASAN}

Pada tahap siklus I pembelajaran dilaksanakan dalam dua pertemuan. Setiap pertemuan melaksanakan pre-test dan post-test untuk mendapatkan hasil perkembangan peserta didik selama pembelajaran. Siklus I membahas materi tentang menentukan kalimat matematika perkalian dan kalimat matematika perkalian dua bilangan sebagai penjumlah berulang. Materi diberikan melalui media powerpoint yang menarik yang disajikan secara urut, sesuai dengan langkah pembelajaran, bahasa yang digunakan juga jelas dan menggunakan pembelajaran problem based learning. Permasalahan yang diberikan ke peserta didik adalah memecahkan masalah bagaimana membuat kalimat perkalian berdasarkan ilustrasi. Berikut ini adalah hasil belajar peserta didik pada siklus I yang bisa dilihat pada tabel berikut.

Table 1. Hasil Belajar Peserta Didik Siklus I

\begin{tabular}{|c|c|c|c|c|c|c|c|c|}
\hline \multirow{4}{*}{ Siklus I } & \multicolumn{4}{|c|}{ Pre test } & \multicolumn{4}{|c|}{ Post test } \\
\hline & \multirow{2}{*}{\multicolumn{2}{|c|}{$\begin{array}{l}\text { Pesdik } \\
\text { Tuntas }\end{array}$}} & \multirow{2}{*}{\multicolumn{2}{|c|}{$\begin{array}{c}\text { Pesdik } \\
\text { Belum } \\
\text { Tuntas }\end{array}$}} & \multicolumn{2}{|c|}{ Pesdik } & \multicolumn{2}{|c|}{ Pesdik } \\
\hline & & & & & Tuntas & $\begin{array}{l}\text { Belum } \\
\text { Tuntas }\end{array}$ & Tuntas & $\begin{array}{l}\text { Belum } \\
\text { Tuntas }\end{array}$ \\
\hline & $\mathrm{Jml}$ & $\%$ & $\mathrm{Jml}$ & $\%$ & $\mathrm{Jml}$ & $\%$ & $\mathrm{Jml}$ & $\%$ \\
\hline Pertemuan 1 & 9 & 43 & 12 & 57 & 11 & 52 & 10 & 48 \\
\hline Pertemuan 2 & 5 & 24 & 16 & 76 & 11 & 52 & 10 & 48 \\
\hline
\end{tabular}

Berdasarkan tabel di atas maka terlihat adanya peningkatan antara pre test dan post test pada pertemuan 1. Setiap peserta didik sudah mengalami peningkatan hasil belajarnya. Pada pertemuang 1 ketuntasan keseluruhan siswa juga mengalami peningkatan, pada pre test hanya terdapat 9 anak yang sudah tuntas, tetapi pada post test bertambah menjadi 11 anak yang sudah tuntas dengan Kriteria Ketuntasan Minimal (KKM) sebesar $\geq 70$. Demikian juga pada pertemuan 2 jumlah peserta didik yang sudah tuntas KKM mengalami peningkatan. Pada pre test ada 5 anak yang tuntas kemudian meningkat menjadi 11 peserta didik yang tuntas setelah melaksanakan post test. Akan tetapi perbandingan antara hasil post test pada pertemuan 1 dan pertemuan 2 belum mengalami perubahan. Baik pada pertemuan 1 
dan 2 siswa yang sudah tuntas didapat jumlah yang sama yaitu 10 siswa.. Persentase ketuntasan keseluruhannya tidak ada peningkatan baik pada pertemuan 1 dan 2 yaitu baru $48 \%$ Berdasarkan refleksi pada siklus I maka diputuskan untuk melanjutkan ke siklus II dikarenakan belum mencapai ketuntasan keseluruhan yang diharapkan. Siklus II membahas materi tentang perkalian bilangan menggunakan bilangan 2, 1 , dan 0 serta table perkalian. Berikut ini adalah hasil belajar peserta didik pada siklus II yang bisa dilihat pada tabel berikut.

Table 2. Hasil Belajar Peserta Didik Siklus II

\begin{tabular}{|c|c|c|c|c|c|c|c|c|}
\hline \multirow{4}{*}{ Siklus II } & \multicolumn{4}{|c|}{ Pre test } & \multicolumn{4}{|c|}{ Post test } \\
\hline & \multirow{2}{*}{\multicolumn{2}{|c|}{$\begin{array}{l}\text { Pesdik } \\
\text { Tuntas }\end{array}$}} & \multirow{2}{*}{\multicolumn{2}{|c|}{$\begin{array}{l}\text { Pesdik } \\
\text { Belum } \\
\text { Tuntas }\end{array}$}} & \multicolumn{2}{|c|}{ Pesdik } & \multicolumn{2}{|c|}{ Pesdik } \\
\hline & & & & & Tuntas & $\begin{array}{l}\text { Belum } \\
\text { Tuntas }\end{array}$ & Tuntas & $\begin{array}{l}\text { Belum } \\
\text { Tuntas }\end{array}$ \\
\hline & $\mathrm{Jml}$ & $\%$ & $\mathrm{Jml}$ & $\%$ & $\mathrm{Jml}$ & $\%$ & $\mathrm{Jml}$ & $\%$ \\
\hline Pertemuan 1 & 8 & 38 & 13 & 71 & 15 & 71 & 6 & 29 \\
\hline Pertemuan 2 & 13 & 62 & 8 & 38 & 20 & 95 & 1 & 5 \\
\hline
\end{tabular}

Berdasarkan tabel di atas terlihat peningkatan antara pre test dan post test pada pertemuan 1. Setiap individu peserta didik sudah mengalami peningkatan hasil belajarnya. Ketuntasan secara keseluruhan juga mengalami peningkatan, pada pre test hanya terdapat 8 anak yang sudah tuntas, tetapi pada post test bertambah menjadi 15 anak yang sudah tuntas dengan Kriteria Ketuntasan Minimal (KKM) sebesar $\geq 70$. Demikian juga terjadi pada pertemuan 2 , jumlah peserta didik yang sudah tuntas KKM mengalami peningkatan. Pada pre test ada 13 anak yang baru tuntas, kemudian sudah meningkat menjadi 20 peserta didik yang tuntas setelah melaksanakan post test. Perbandingan antara hasil post test pada pertemuan 1 dan pertemuan 2 juga terdapat perbedaan. Pada pertemuan 1 peserta didik yang sudah tuntas hanya ada 15 anak, sedangkan pada pertemuan 2 sudah meningkat menjadi 20 anak. Persentase ketuntasan klasikalnya meningkat, jika pertemuan 1 hanya $71 \%$ maka pada pertemuan 2 menjadi 95\%.

Setelah melakukan refleksi pada siklus II, maka diputuskan untuk melanjutkan pada siklus III. Hal ini dilakukan agar mengetahui sejauh mana penggunaan media power point tidak hanya meningkatkan tetapi juga mempertahankan hasil belajar peserta didik. Pada siklus III materi yang diajarkan adalah perkalian dengan hasil yang sama dan sifat komutatif pada perkalian. Hasil belajar peserta didik dapat dilihat pada tabel berikut.

Table 2. Hasil Belajar Peserta Didik Siklus III

\begin{tabular}{|c|c|c|c|c|c|c|c|c|}
\hline \multirow{4}{*}{ Siklus III } & \multicolumn{4}{|c|}{ Pre test } & \multicolumn{4}{|c|}{ Post test } \\
\hline & \multirow{2}{*}{\multicolumn{2}{|c|}{$\begin{array}{l}\text { Pesdik } \\
\text { Tuntas }\end{array}$}} & \multirow{2}{*}{\multicolumn{2}{|c|}{$\begin{array}{l}\text { Pesdik } \\
\text { Belum } \\
\text { Tuntas }\end{array}$}} & \multicolumn{2}{|c|}{ Pesdik } & \multicolumn{2}{|c|}{ Pesdik } \\
\hline & & & & & Tuntas & $\begin{array}{l}\text { Belum } \\
\text { Tuntas }\end{array}$ & Tuntas & $\begin{array}{l}\text { Belum } \\
\text { Tuntas }\end{array}$ \\
\hline & $\mathrm{Jml}$ & $\%$ & $\mathrm{Jml}$ & $\%$ & Jml & $\%$ & $\mathrm{Jml}$ & $\%$ \\
\hline Pertemuan 1 & 14 & 67 & 7 & 33 & 17 & 81 & 4 & 19 \\
\hline Pertemuan 2 & 13 & 62 & 8 & 38 & 20 & 95 & 1 & 5 \\
\hline
\end{tabular}

Pada pertemuan 1 ketuntasan secara keseluruhan mengalami peningkatan, pada pre test hanya terdapat 14 anak yang sudah tuntas, tetapi pada post test bertambah menjadi 17 anak yang sudah tuntas dengan Kriteria Ketuntasan Minimal (KKM) sebesar $\geq 70$. Demikian juga pada pertemuan 2 jumlah peserta didik yang sudah tuntas KKM mengalami peningkatan. Pada pre test ada 13 anak yang baru tuntas, sudah meningkat menjadi 20 peserta didik yang tuntas setelah melaksanakan post 
test. Perbandingan antara hasil post test pada pertemuan 1 dan pertemuan 2 juga terdapat perbedaan. Pada pertemuan 1 peserta didik yang sudah tuntas hanya ada 17 anak, sedangkan pada pertemuan 2 sudah meningkat menjadi 20 anak. Persentase ketuntasan klasikalnya meningkat, jika pertemuan 1 hanya $81 \%$ maka pada pertemuan 2 menjadi 95\%.

Dari tiga siklus yang sudah dilaksanakan selama 6 pertemuan dapat dipastikan bahwa media powerpoint dapat meningkatkan hasil belajar peserta didik pada mupel matematika Kelas II di SD Negeri 2 Semawungdaleman. Hal ini sesuai denagn konsep atau teori yang diungkapkan oleh Steffi Adam dan Muhammad Taufik Syastra (2015) bahwa media pembelajaran adalah segala sesuatu baik berupa fisik maupun teknis dalam proses pembelajaran yang dapat membantu guru untuk mempermudah dalam menyampaikan materi pelajaran kepada siswa sehingga memudahkan pencapaian tujuan pembelajaran yang telah dirumuskan. Hal tersebut benar adanya dengan media pembelajaran membantu guru untuk mempermudah penyampaian materi dan siswa akhirnya mencapai tujuang pembelajaran yaitu mampu menentukan perkalian sebagai penjumlahan berulang dengan baik sehiggan pengetahuan yang diperoleh dapat terus tersimpan dengan baik apalagi media yang digunakan berupa Microsoft powerpoint yang dapat menjadikan presentasi dari guru menarik siswa untuk belajar sesui dengan yang diungkapan oleh Razaq (dalam Sukiman, 2012:213) mengemukakan bahwa dengan Microsoft Office Power Point ini kita dapat merancang dan membuat presentasi yang lebih menarik dan profesional. Hasil penelitian ini juga sesuai dengan penelitian sebelumnya yang dilakukan oleh Budi Rahmanto (2013) yang membuktikan bahwa media power point dapat meningkatkan hasil belajar dari peserta didik.

\section{SIMPULAN}

Penggunaan media powerpoint dapat meningkatkan hasil belajar matematika peserta didik kelas II pada materi perkalian sebagai penjumlahan berulang. Peningkatan yang terjadi karena adanya minat dan rasa yang berkesan dari peserta didik ketika melihat penyuguhan materi dengan menggunakan media powerpoint. Peserta didik telah menemukan hal baru yang menyenangkan dan menarik mereka. Sesuatu yang berbeda dari hanya sekedar papan tulis dan guru yang berbicar di depan kelas. Media powerpoint memberikan tampilan baik secara audio maupun visual. Meskipun begitu media powerpoint tidak seharusnya menggantikan peran guru sepenuhnya Selain karena media yang digunakan peserta didik belajar untuk menemukan pengetahuannya sendiri dari permasalahan yang guru berikan melalui LKPD. Atas hasil dari penelitian maka guru harus bisa membuat media pembelajaran yang menarik minat dan motivasi siswa dalam belajar yaitu dengan menggunakan media power point. Sehingga hasil belajar siswa meningkat secara signifikan.

\section{DAFTAR PUSTAKA}

Adam. Steffi dan Muhammad Taufik Syastra. (2015). Pemanfaatan Media Pembelajaran Berbasis Teknologi Informasi Bagi Siswa Kelas X Sma Ananda Batam. Dalam CBIS Journal, Volume 3 No 2: 79 diakses pada tanggal 6 November 2020 pukul 16.16 WIB file://C:/Users/User/Downloads/113-187-1-SM.pdf

Arsyad, A. (2014). Media Pembelajaran. Jakarta: Raja Grafindo Persada. .Jurnal.untan.ac.id. no. 6 vol. 12 diakses pada tanggal 14 Oktober 2020 pada pukul 01.28 dari https://jurnal.untan.ac.id/index.php/jpdpb/article/view/23229

Haryanto, 2012: dalam artikel "pengertian pendidikan menurut para akhli http://belajarpsikologi. com/pengertianpendidikan-menurut-ahli/ diakes pada 
tanggal 9 april 2017 diakses pada tanggal 22 November 2020 pada pukul 03.30 WIB dari http://eprints.umm.ac.id/41375/3/BAB\%20II.pdf

Jihad, Asep. 2010. Evaluasi Pembelajaran. Yogyakarta: Multi Press. diakses pada tanggal 14 Oktober 2020 pada pukul 02.05 WIB dari http://mahasiswa.mipastkipllg.com/repository/Jurnal\%20skripsi.pdf

Rahmanto Budi. 2013. Upaya Meningkatkan Prestasi Belajar IPS Menggunakan Media Powerpoint Pada Siswa Kelas IV SD Negeri Timbulharjo Depok Sleman. diakses pada tanggal 17 Novembar 2020 pada pukul 15.47 dari https://core.ac.uk/download/pdf/33512798.pdf

Sudijono, Anas.2011.Pengantar Evaluasi Pendidikan, (Jakarta: PT Rajagrafindo Persada), hlm. 49 diakses pada tanggal 22 November pada pukul pukul 02.31 WIB dari http://eprints.walisongo.ac.id70213BAB\%20II.pdf

Sukiman. 2012. Pengembangan Media Pembelajaran. Yogyakarta : Pedagogja diakses pada tanggal 04 Oktober 2020 pada pukul 02.05 WIB dari http://mahasiswa.mipastkipllg.com/repository/Jurnal\%20skripsi.pdf

Syah, Muhibbin.2009.Psikologi Pendidikan dengan Pendekatan Baru, (Bandung: PT Remaja Rosdakarya), hlm. 65 diakses pada tanggal 22 November 2020 pada pukul 02.31 WIB dari http://eprints.walisongo.ac.id70213BAB\%20II.pdf 